\title{
Experimental and Analytical Study of Slender Reinforced Concrete Shear Wall under Cyclic In-Plane Lateral Load
}

\author{
Diego Sosa, Diego Arévalo, E. David Mora, M. Belén Correa, \\ Diego Albuja, and Christian Gómez
}

\begin{abstract}
Escuela Politécnica Nacional, Facultad de Ingeniería Civil y Ambiental, Centro de Investigación de la Vivienda (CIV-EPN), Quito, Ecuador
\end{abstract}

Correspondence should be addressed to Diego Sosa; diego.sosac@epn.edu.ec

Received 3 March 2017; Accepted 15 August 2017; Published 24 September 2017

Academic Editor: Michael W. S. Lau

Copyright (c) 2017 Diego Sosa et al. This is an open access article distributed under the Creative Commons Attribution License, which permits unrestricted use, distribution, and reproduction in any medium, provided the original work is properly cited.

This study describes a slender reinforced concrete shear wall experimental test under in-plane cyclic lateral load, and the development of an analytical model which uses the fiber method approach to consider hysteretic nonlinear constitutive material models behavior. The shear wall tested had bending behavior, since the amount of longitudinal reinforcing bars produced weak bending capacity compared to the shear strength. The analytical model tries to represent global and local behavior of the wall, and its calibration is based on reaching experimental parameters like area enclosed and secant stiffness on every loop. After the analytical model was calibrated, the relation between some performance points and damage states observed during the test is studied.

\section{Introduction}

Many authors have studied experimental concrete shear wall models tested in a laboratory under cyclic in-plane lateral load and have developed analytical models which represent with good accuracy the global and local hysteretic experimental behavior. Park et al. (1987) contributed to the state of the art in modeling of reinforced concrete behavior and structural analysis, for developing the analytical tool IDARC (Inelastic Damage Analysis of Reinforced Concrete Frame-Shear-Wall Structures) [1]. This tool was developed to support experimentation, design processes, and represent damage by using some original constitutive models.

Wallace and Moehle (1992) described an analytical procedure to determine the need for concrete confinement at the boundaries of structural walls in building subjected to earthquakes and concluded that confinement is not required for symmetrically reinforced rectangular wall cross sections but could be necessary at the extremities of walls having T, L, or other similarly shaped cross sections [2].

Ile and Reynouard (2000) proposed a constitutive model for predicting the cyclic response of reinforced concrete structures; the model adopted the concept of a smeared crack approach with orthogonal fixed cracks and assumed a plane stress condition; this model was compared with experimental results of a shear wall tested at NUPEC's Tadotsu Engineering Laboratory and finally after several models and comparisons the numerical results showed good correlation between the predicted and the actual response [3].

Hidalgo et al. (2002) studied the behavior of reinforced concrete walls that exhibit the shear mode of failure; this study tested 26 full-scale specimens subjected to cyclic horizontal displacements of increasing amplitude; test parameters were the aspect ratio of the walls, the amount of vertical and horizontal distributed reinforcement, and the compressive strength of concrete. The investigation gave conclusions about the dissipation characteristics and the strength deterioration after maximum strength shown by the walls and the influence of vertical distributed reinforcement on the seismic behavior of walls [4].

Thomsen IV and Wallace (2004) have taken the results of experimental studies of moderate-scale, slender wall specimens with rectangular-shaped and T-shaped cross sections and verified the results predicted using displacement-based design and concluded that displacement-based design is both a powerful and flexible tool for assessing wall detailing requirements [5]. 




Figure 1: Test implementation.

Su and Wong (2007) tested walls in the form of a slender vertical cantilever with an aspect ratio of 4 , fabricated with high strength concrete and high longitudinal ratio, and identified that axial load ratio is an indispensable parameter for consideration in seismic performance assessment of reinforced concrete shear walls [6].

Kuang and Ho (2008) investigated the seismic behavior and displacement ductility of the shear walls; in this study large-scale nonseismically detailed, squat reinforced concrete shear walls with aspect ratios of 1.0 and 1.5 are tested, as practiced in low to moderate probability of seismic occurrence regions, under reversed cyclic loading, and it is shown that an ordinary squat shear wall with nonseismic design and detailing may not have sufficient ductility to respond adequately to an unexpected moderate earthquake [7].

After reviewing several investigations, and with the aim of contributing with the state of the art of reinforced concrete shear walls, this study proposes a slender reinforced concrete shear wall with relation between height of the applied load and length $h_{w} / l_{w}$ equal to 2.8 . The wall was subjected to a cyclic in-plane lateral load at CIV-EPN at Ecuador, and it is intended to use experimental results to make a model using SeismoStruct. Finally this study verifies performance criteria between experimental and analytical models, as well as checking the influence of shear on slender walls.
The proposed analytical model considers the shear wall as an inelastic frame force-based element, with nonlinear behavior of its materials, using the following constitutive models: bilinear steel model (stl_bl); Menegotto-Pinto steel model (stl_mp) [8]; Dodd-Restrepo steel model (stl_dr) [9]; and Mander et al. nonlinear concrete model (con_ma) [10]. Finally the model establishes the best constitutive material combination that converges better with the experimental results. The main goal of this study is to develop a nonlinear structural model using the fiber method approach and validate it by comparing with experimental results obtained in laboratory. One of the most important parameters of shear walls is the relation between height and length $h_{w} / l_{w}$. This relation is known as aspect ratio. Shear walls with $h_{w} / l_{w}>2$ are called slender shear walls and behave as a cantilever beam, so in these walls bending effects have the main contribution on the global wall behavior.

\section{Shear Wall Geometry and Design}

The shear wall tested was $4.40 \mathrm{~m}$ high and $1.5 \mathrm{~m}$ long. Their boundary elements have a section of $0.3 \mathrm{~m} \times 0.3 \mathrm{~m}$, and its web thickness was $0.15 \mathrm{~m}$. In Figure 1 it is possible to see general dimensions, shear wall components, and test implementation. 


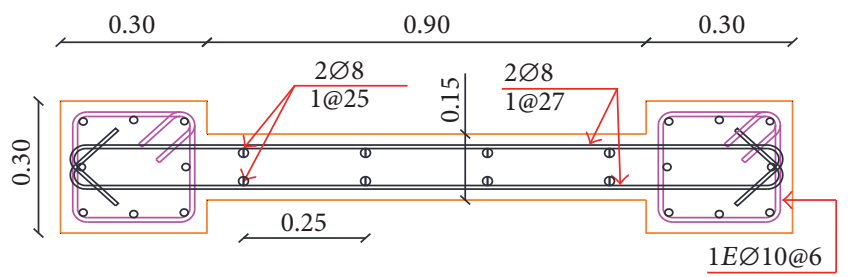

(1) $8 \varnothing 8$

○ $16 \varnothing 10$

FIgURE 2: Reinforcement details.

TABLE 1: Nomenclature.

\begin{tabular}{lc}
\hline Code & Description \\
\hline L-SG\# & Left strain gauge on rebar \\
R-SG\# & Right strain gauge on rebar \\
SG\# & Strain gauge on transverse reinforcement \\
\hline
\end{tabular}

According to ACI 318-14 [12], shear strength could be calculated using

$$
V_{n}=V_{c}+V_{s}=\ell_{w} t\left[\alpha_{c} \lambda\left(\sqrt{f^{\prime} c}\right)+\rho_{t} f_{y}\right] .
$$

In order to determine bending strength of the concrete shear wall, interaction diagram could be calculated using its transversal section shown in Figure 2.

The shear wall was designed using ACI 318-14 [12]. Geometry and reinforcement were selected to get flexural failure. The mean concrete compressive strength obtained in laboratory tests was $21.62 \mathrm{MPa}$, and mean steel tensile strength was $492.37 \mathrm{MPa}$.

\section{Instrumentation and Loading Protocol}

The shear wall was instrumented with a load cell and two linear variable differential transformers (LVDT), and strain gauges were attached to the rebar and transverse reinforcement. Figure 3 shows wall instruments, and Table 1 has the nomenclature of each strain gauge.

Figure 4 shows the loading protocol used to test the concrete shear wall, and Figure 5 shows the experimental hysteresis cycles of the shear wall under in-plane lateral load. Furthermore, it is possible to see in Figure 5 strength degradation after four cycles of yielding. The loading protocol tried to get the performance of the wall from its linear behavior to its yielding by the increasing of the lateral load on every cycle and after yielding by the increasing of lateral displacement.

\section{Experimental Test Observations}

In Figure 6 is possible to see an evolution of cracks at the end of each cycle. Furthermore, it shows a percentage of height with damage and a thickness of representative cracks in millimeters at the bottom of the shear wall. After each cycle the increase of cracks was identified and painted, and some measurements like the cracking height on the wall surface and the crack width were determined by a measuring tape and a crack width ruler, respectively. Italic, bold, and bold italic fonts indicate a classification for slight, moderate, and extensive damage; the criteria considered for this classification are presented in Table 2.

At the end of the test, it is possible to observe a crack at the base of the structure, and it tends to be horizontal. This huge crack demonstrates a flexural failure. Table 2 describes the shear wall damage during lateral load.

In order to compare test observations, the FEMA 306 component damage classification is presented in Table 3 [13].

In fact, it is possible to compare both tables and make an equivalence. At the end of the test, the shear wall has an extreme damage according to FEMA 306 [13], which means it requires replacement. In fact, shear wall shows yielding of its rebar and major spalling of unconfined concrete.

\section{Description of Models}

As described above, the tested structure is a shear wall with a height of $4.20 \mathrm{~m}$ on the applied load and a length of $1.5 \mathrm{~m}$ parallel to the direction of the applied load; hence a length to height ratio of 0.36 was obtained. Shear walls up to a ratio of 0.2 can be analyzed acceptably with bending theory [14] and according to concrete design codes, as ACI 318-14 [12], they could be considered with flexural behavior against a lateral load in-plane direction if they have a ratio of 0.4. Then in this case it would be necessary calculate shear deformation. The current shear deformation influence on this tested shear wall in the applied force direction is approximately calculated below using Virtual work:

$$
\frac{\Delta_{s}}{\Delta_{b}}=\frac{f \int_{0}^{L}(V v / A G) d x}{\int_{0}^{L}(M m / E I) d x}=f \frac{3 E I}{A G h_{w}{ }^{2}} .
$$

with $\Delta_{s}$ and $\Delta_{b}$ being the lateral deformation by shear and bending, respectively, $f$ a shape factor due to a maximum and average shear stress along the section, $A$ the area of the section, $I$ the major inertia moment of the section, $G$ the shear modulus, $E$ the Young modulus, $h_{w}$ the height of the element, and $V, v, M$, and $m$ the real and virtual shear and the real and virtual moment, respectively. Simplifying the model as if it is isotropic: $G=E / 2(1+\mu)$ and taking the Poisson Modulus $\mu=0.2$.

$$
\frac{\Delta_{s}}{\Delta_{b}}=\frac{7.2 f r^{2}}{h_{w}{ }^{2}} .
$$

with $r$ being the radius of gyration $\left(r^{2}=I / A\right)$, and a cantilever element of an effective length of $k h_{w}=2 h_{w}$; then

$$
\frac{\Delta_{s}}{\Delta_{b}}=\frac{28.8 f}{\left(k h_{w} / r\right)^{2}} .
$$

Resulting from this structure, shear deformation related to bending deformation is around $\Delta_{s}=0.15 \Delta_{b}$. To check up on the shear influence and other influence parameters a framed-type model was elaborated. At the beginning it was 


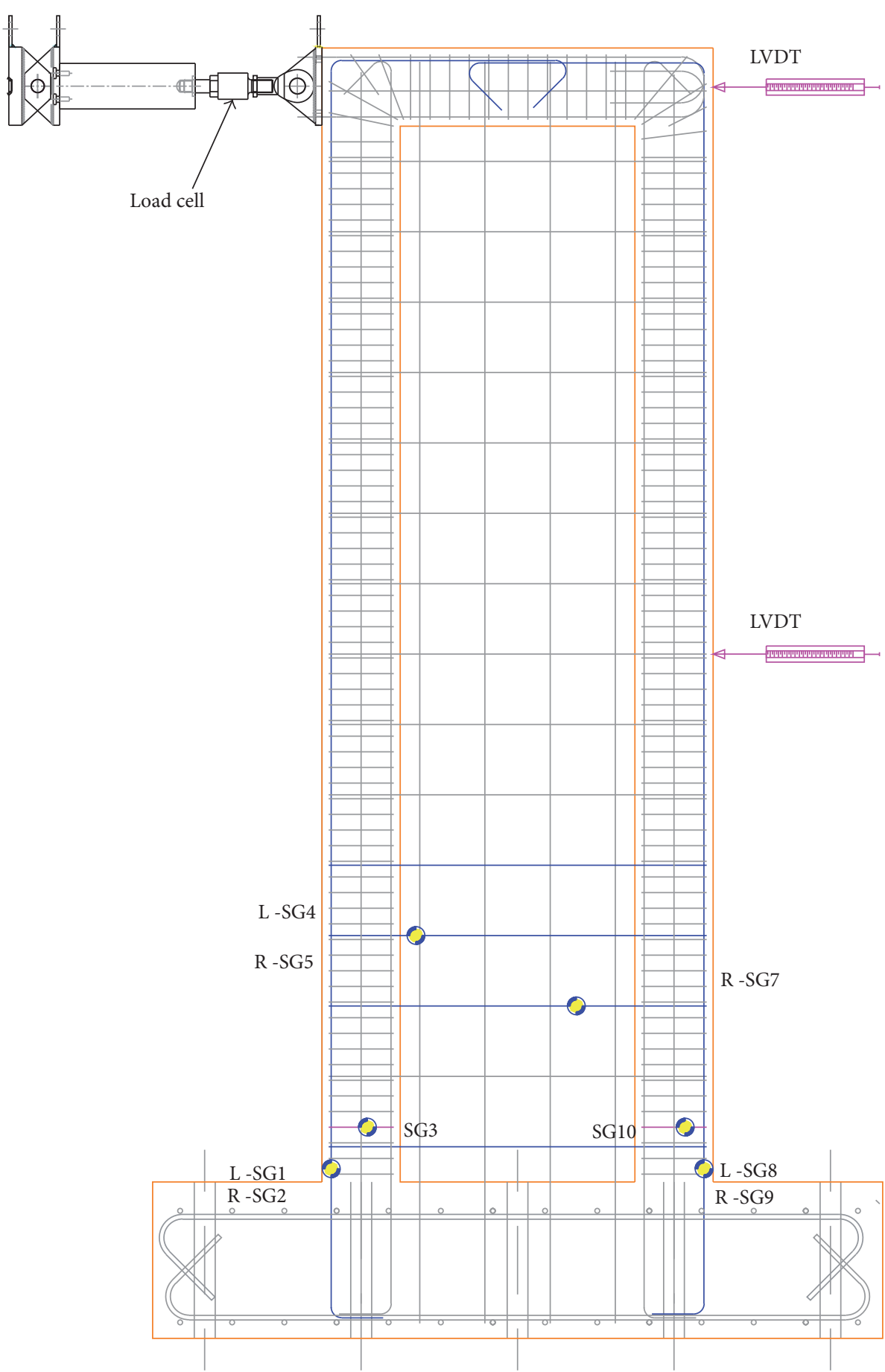

FIGURE 3: Instrumentation of shear wall.

only working in flexure and later it was compared against a model with a shear spring that takes into account all shear deformation. Also other parameters as constitutive models were compared. To shape a shear wall with those characteristics using only a frame element and to simulate its linear and nonlinear behavior, a fiber model was made in the program SeismoStruct [11]; it is a freely downloadable Finite Element package capable of making static and dynamic analysis of framed-type structures, regarding geometric and material nonlinearities.

One important reason to use SeismoStruct was because it allows studying the historical performance of every section and component selected, and thus the comparison between the real and the mathematical model made can be more illustrative.

The fiber model made is an inelastic force-based frame element joined with its base by a linear shear spring, with 


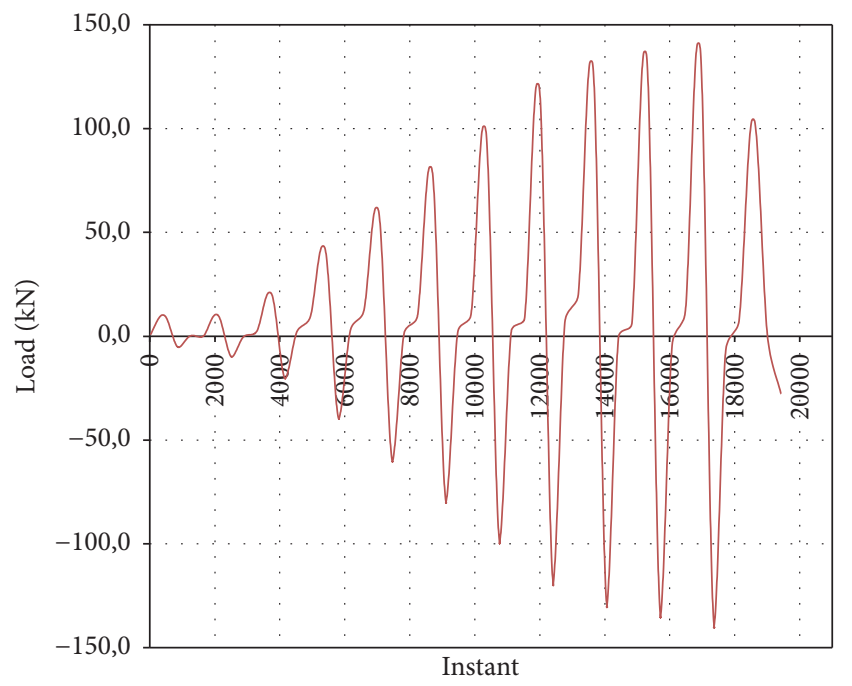

FIGURE 4: Loading protocol.

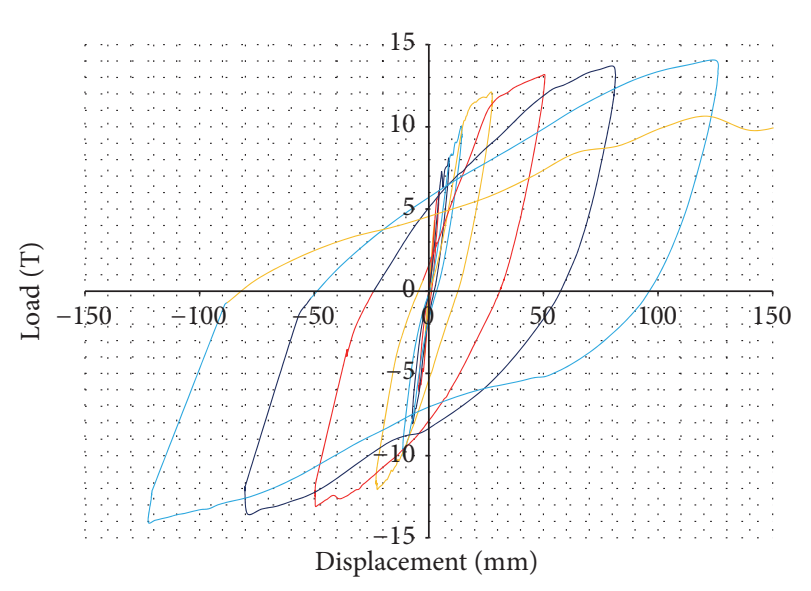

FIGURE 5: Hysteresis cycles.

TABLE 2: Test observations.

\begin{tabular}{ll}
\hline Damage state & $\begin{array}{l}\text { Description } \\
\text { (test observations) }\end{array}$ \\
\hline Slight & $\begin{array}{l}\text { Insignificant or minor damage. It does not } \\
\text { need repair. Less than } 30 \% \text { of its height with } \\
\text { cracks, and they are less than or equal to } 1 \mathrm{~mm} \\
\text { thickness. }\end{array}$ \\
\hline Moderate & $\begin{array}{l}\text { Tolerable damage. It needs some repair. Less } \\
\text { than } 60 \% \text { of its height with cracks, and they are } \\
\text { less than or equal to } 2 \text { mm thickness. }\end{array}$ \\
\hline \multirow{3}{*}{ Extensive } & $\begin{array}{l}\text { Significant, substantial, or major damage. It } \\
\text { needs to be demolished. More than } 60 \% \text { of its } \\
\text { height with cracks, and many of them are more } \\
\text { than } 2 \text { mm in thickness. Unconfined concrete } \\
\text { has substantial spalling. }\end{array}$ \\
\hline
\end{tabular}

a static time-history load equal to the real one; the frame element was divided into five sections to study the particular behavior of them.
TABle 3: Component damaged classification [13].

\begin{tabular}{ll}
\hline $\begin{array}{l}\text { Severity of } \\
\text { damage }\end{array}$ & Description \\
\hline Insignificant & $\begin{array}{l}\text { Damage does not significantly affect structural } \\
\text { properties in spite of a minor loss of stiffness. } \\
\text { Restoration measures are cosmetic unless the } \\
\text { performance objective requires strict limits on } \\
\text { nonstructural component damage in future } \\
\text { events. }\end{array}$ \\
\hline Slight & $\begin{array}{l}\text { Damage has a small effect on structural } \\
\text { properties. Relatively minor structural } \\
\text { restoration measures are required for restoration } \\
\text { for most components and behavior modes. }\end{array}$ \\
\hline Moderate & $\begin{array}{l}\text { Damage has an intermediate effect on structural } \\
\text { properties. The scope of restoration measures } \\
\text { depends on the component type and behavior } \\
\text { mode. Measures may be relatively major in some } \\
\text { cases. }\end{array}$ \\
\hline Heavy & $\begin{array}{l}\text { Damage has a major effect on structural } \\
\text { properties. The scope of restoration measures is } \\
\text { generally extensive. Replacement or } \\
\text { enhancement of some components may be } \\
\text { required. }\end{array}$ \\
\hline $\begin{array}{l}\text { Damage has reduced structural performance to } \\
\text { unreliable levels. The scope of restoration } \\
\text { measures generally requires replacement or } \\
\text { enhancement of components. }\end{array}$ \\
\hline
\end{tabular}

\section{Fiber Model}

This model is based on flexibility fiber elements; they are divided into longitudinal fibers with particular areas and geometric characteristics along them as shown in Figure 7. The RC section was modeled with three different types of fibers to represent unconfined concrete, confined concrete, and rebar.

The fibers follow a uniaxial stress-strain linear and nonlinear relation of each particular material, and although there is not an explicit constitutive relation between sections they stem from integration of the outcomes and it is a method which can provide good results [15].

The integration section method used in this case was the Gauss-Lobatto one, because it was preferable to work obtaining a flexibility matrix of all the elements, since if they are analyzed based on a force field the model can be accurate enough with few integration sections [16].

Also, inasmuch as the convergence being something difficult to achieve, some values such as the number of fibers and the integration section had to vary until the goal was reached. At the end the model was made with five longitudinal sections and five hundred fibers.

\section{Shear Spring}

A model of a shear spring which takes into account all the shear deformation was included to get good accuracy between experimental and analytical results. The spring that was chosen considers the shear strength degradation [17]; 


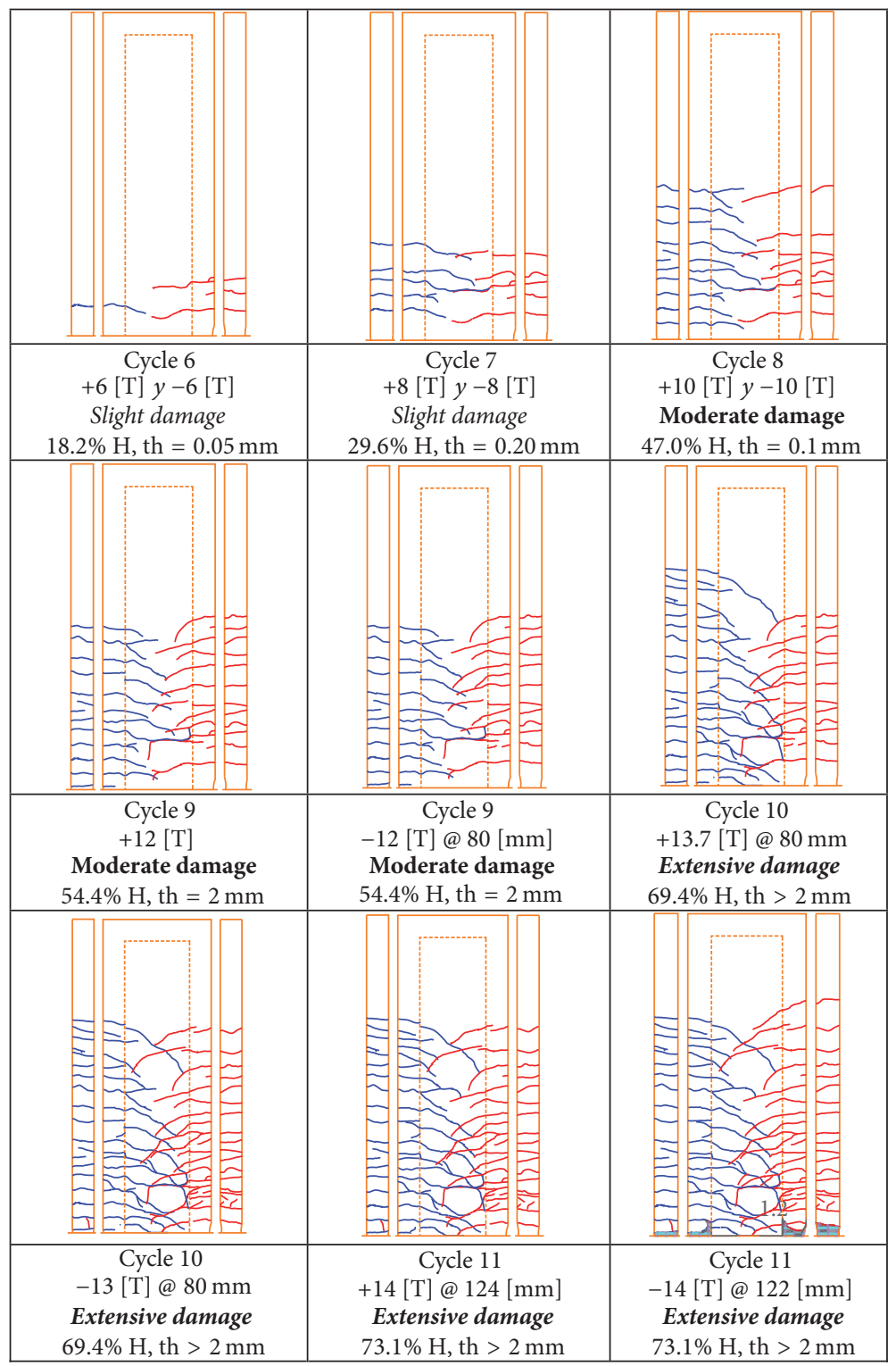

FIGURE 6: Crack patterns.

but, the structure stress got to be below the maximum shear allowed before degradation; then this spring only worked elastically.

\section{Constitutive Concrete Material}

This study uses the computational software for nonlinear analysis SeismoStruct mentioned above in which there are many constitutive concrete materials, but the shear wall model studied here considers only one concrete material named as con_ma in the SeismoStruct library. The material con_ma has the proposal of Mander et al. [10] for unconfined and confined concrete, and it also has the cyclic nonlinear behavior proposed by Martinez-Rueda and Elnashai [18]. Con_ma represents the uniaxial nonlinear behavior for each concrete fiber obtained in the discretization of the transverse section, so the constitutive material assigned on the wall section could be unconfined or confined as it is shown in Figure 8. The wall section has two parts: the edge sections and the core section, and both of them have unconfined material for the recovering and confined material for concrete inside the hoops.

Mander et al. [10] proposed that unconfined concrete material is modified in strength and strain when there is transverse lateral reinforcement to confine it, so the constitutive material for confined concrete gains ductility and resistance (Figure 9). The properties used to define the constitutive model for unconfined concrete are listed in Table 4, and they are modified by confinement factors listed in Table 5 which increase strength and strain because of the presence of transverse lateral reinforcement.

The fiber method approach permits recording the time series of the constitutive behavior in any transverse section 

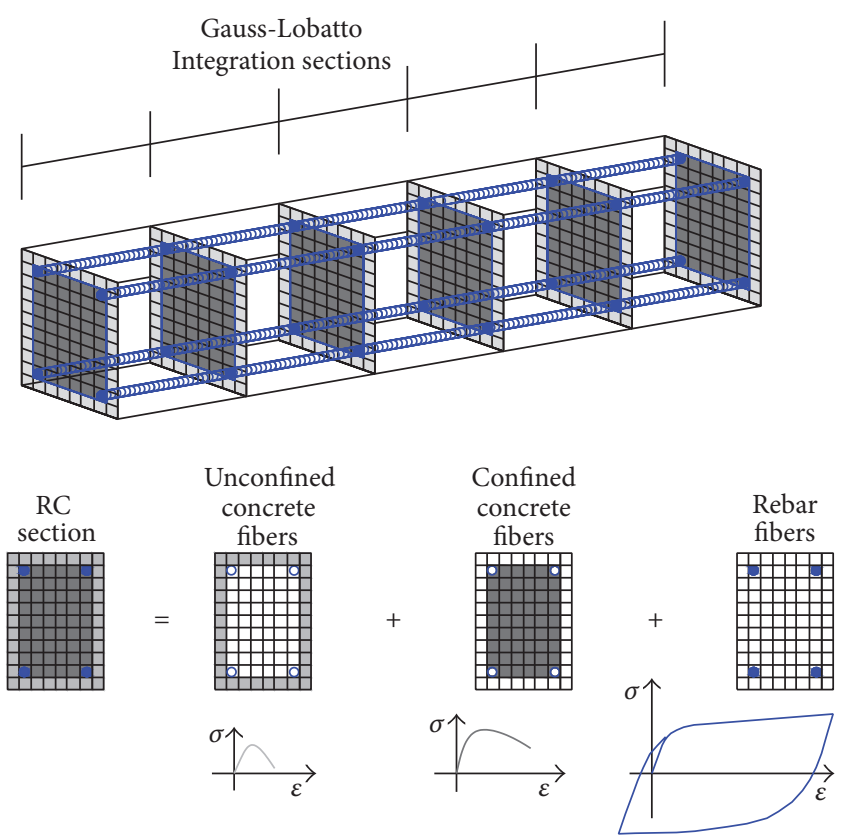

Figure 7: Element fiber model [11].

TABLE 4: Unconfined concrete properties.

\begin{tabular}{lcc}
\hline Parameter & Value & Units \\
\hline Compressive strength, $f_{c}$ & 21,75 & $\mathrm{MPa}$ \\
Tensile strength, $f_{t}$ & 2,175 & $\mathrm{MPa}$ \\
Modulus of elasticity, $E_{c}$ & 21919,59 & $\mathrm{MPa}$ \\
Strain at peak stress, $\varepsilon_{c}$ & 0,0025 & - \\
Specific weight, $\Upsilon$ & 24 & $\mathrm{KN} / \mathrm{m} 3$ \\
\hline
\end{tabular}

TABLE 5: Concrete confinement factors.

\begin{tabular}{lc}
\hline Sections & Factors \\
\hline Unconfined & 1 \\
Web confinement/core & 1 \\
Edge confinement & 1,33 \\
\hline
\end{tabular}

fiber, so in Figure 10 there is a fiber comparison between confined concrete and unconfined concrete fibers. It is shown that unconfined concrete gets to its maximum stress, but the confined concrete does not.

\section{Constitutive Steel Material}

The steel material was used as a setting parameter to calibrate the analytical model, thus there was used three steel constitutive materials presented in the SeismoStruct library. These material models have different levels of complexity, for the number and kind of data required to describe their behavior. The material models used are bilinear, Dodd-Restrepo, and Menegotto-Pinto. Each model is briefly described below.

9.1. Bilinear Steel Model. This material is called stl_bl in SeismoStruct library, and it is the simplest and one of the
TABLE 6: Bilinear steel model parameters.

\begin{tabular}{lcc}
\hline Parameter & Value & Units \\
\hline Modulus of elasticity, $E_{s}$ & 228180 & $\mathrm{MPa}$ \\
Postyield modulus, $E_{s p}$ & 1551,33 & $\mathrm{MPa}$ \\
Yield strength, $f_{y}$ & 418,547 & $\mathrm{MPa}$ \\
Strain hardening & 0,00679 & - \\
parameter, $\mu=E_{s p} / E_{s}$ & 0,1 & - \\
Fracture/buckling strain & 78 & $\mathrm{KN} / \mathrm{m} 3$ \\
\hline Specific weight & &
\end{tabular}

most efficient models of reinforcing steel. The stl_bl permits having good accuracy; however there are other models which can represent better the uniaxial steel behavior. This material can be defined by using two points as it is shown in Figure 11, and it has two slopes that determine its constitutive model. The first slope $E_{s}$ is the modulus of elasticity, and the second slope $E_{s p}$ is the post-yield modulus. In the parameter list of stl_bl the program permits the user to enter also the strain at which the fracture or buckling happened, but during the experimental test none of these phenomena were identified. The parameters used to define the constitutive material are listed in Table 6.

9.2. Dodd-Restrepo Steel Model. This model is based on macroscopic observations, and the values of stress and strain are obtained considering the instantaneous geometric properties of steel. The model focuses only on the behavior of the material, so it does not consider the buckling effect of the rebar. It also proposes a way of representing the Bauschinger effect [9]. This phenomena is a reduction in the elastic limit and a softening of the cyclic stress-strain curve of the rebar constitutive material [19]. In SeismoStruct library this material model is called stl_dr, and it considers other effects like reduction of the unloading modulus with the plastic strain, and reduction of the ultimate tensile strain as a function of the maximum compressive strain [11]. This material model is completely defined by four points as it is shown in Figure 12, and the parameters used to define the constitutive material are listed in Table 7.

9.3. Menegotto-Pinto Steel Model. This material was proposed by Menegotto and Pinto [8], and it is a versatile material model that considers some phenomena like isotropic hardening [20], Bauschinger effects, pinching of the hysteretic loops, bucking, and fracture [8]. In SeismoStruct [11] this material is called stl_mp, and the parameters used to define its behavior are presented in Table 8 and Figure 13.

Stl_mp model does not consider a yield plate in its stress-strain curve or have a strain hardening section. To include the effect of strain hardening stl_mp model uses the simplification proposed in stl_bl model where after yielding there is a line that joins the yielding point $\left(\varepsilon_{y}, \sigma_{y}\right)$ with the peak load point $\left(\varepsilon_{\text {ult }}, \sigma_{\text {ult }}\right)$.

Both models stl_dr and stl_mp consider Bauschinger effect; however this effect can be modified in stl_mp by using some parameters listed in Table 8. These parameters which 


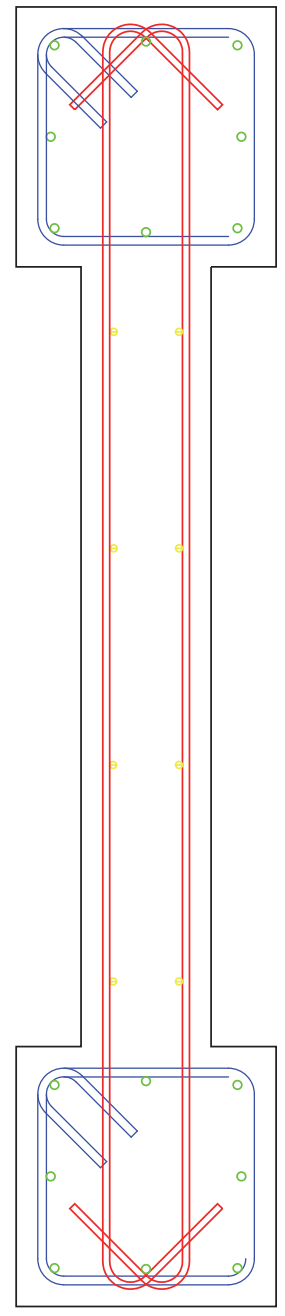

(a) Wall sections

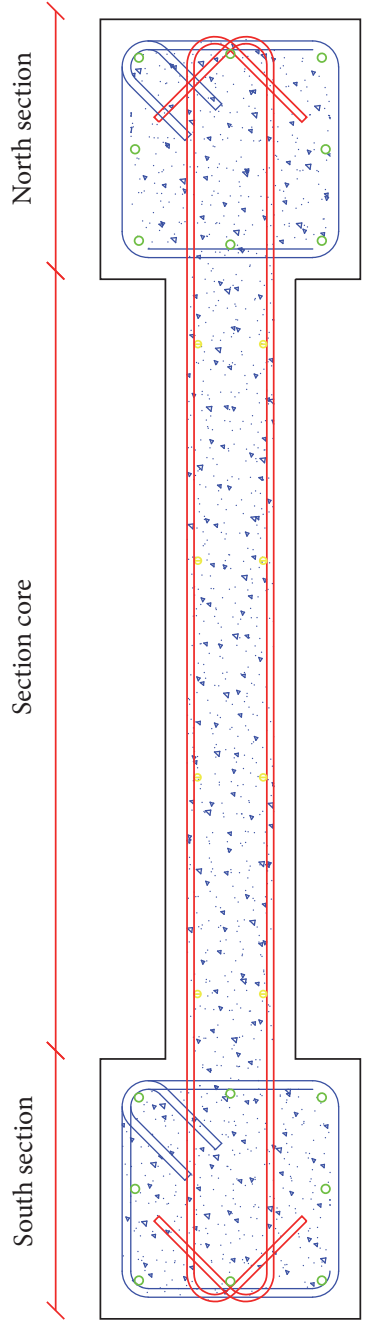

(b) Confined concrete

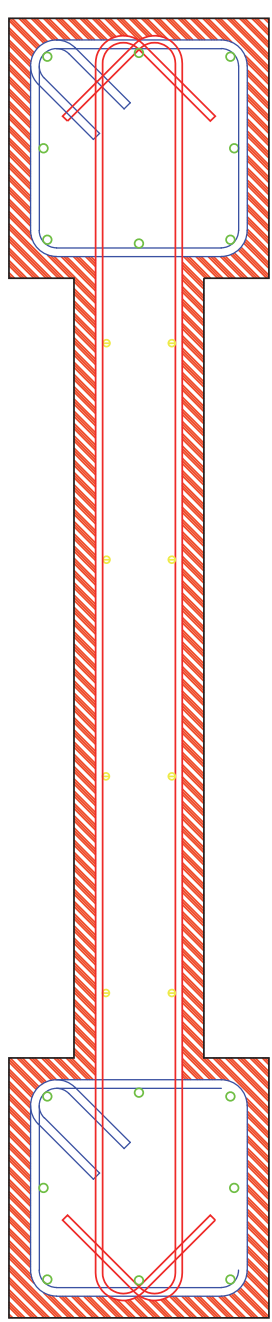

(c) Unconfined concrete

FIGURE 8: Wall concrete sections.

TABLE 7: Dodd-Restrepo steel model parameters.

\begin{tabular}{lcc}
\hline Parameter & Value & Units \\
\hline Modulus of elasticity, $E_{s}$ & 228180 & $\mathrm{MPa}$ \\
Yield strength, $f_{y}$ & 418,547 & $\mathrm{MPa}$ \\
Stress at peak load, $f_{\text {ult }}$ & 578,592 & $\mathrm{MPa}$ \\
Strain at initiation of strain hardening curve, $\varepsilon_{\text {sh }}$ & 0,01605 & - \\
Strain at peak load, $\varepsilon_{\text {ult }}$ & 0,105 & - \\
Strain at the intermediate point on of strain hardening curve, $\varepsilon_{\text {sh2 }}$ & 0,06052 & - \\
Stress at the intermediate point on of strain hardening curve, $f_{\text {sh2 }}$ & 525,042 & $\mathrm{MPa}$ \\
Specific weight & 78 & $\mathrm{KN} / \mathrm{m} 3$ \\
\hline
\end{tabular}

modify the shape of the transition curves can also produce a pinching of the hysteretic loops in the constitutive model of steel, for there is a reduction of strength and reduction of area enclosed in each loop. Because the effects of isotropic hardening were not considered, default parameters in this phenomenon were used in SeismoStruct. The pinching effect can easily be seen by comparing Figures 12 and 13 because the areas enclosed are different in both schemes. There are also changes in strength; while both have the same stress in the first tension upload, after unloading there are differences in stress for common strains.

In SeismoStruct the option to display the stress-strain behavior for any fiber is available, so in Figure 14 a comparison of the most strained rebar fiber for the three reinforcing 


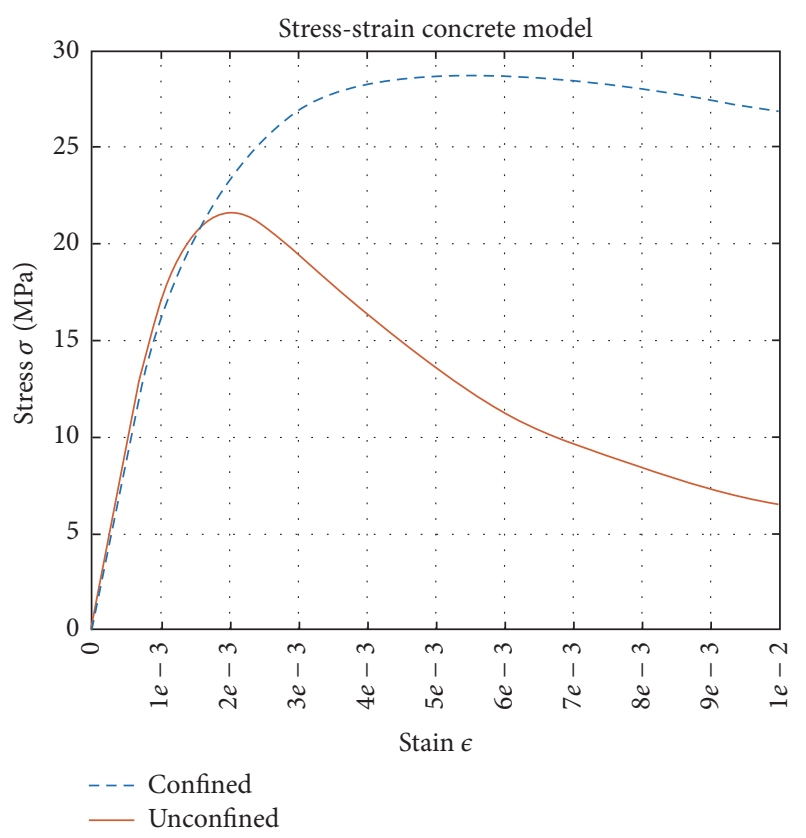

FIGURE 9: Concrete constitutive model.

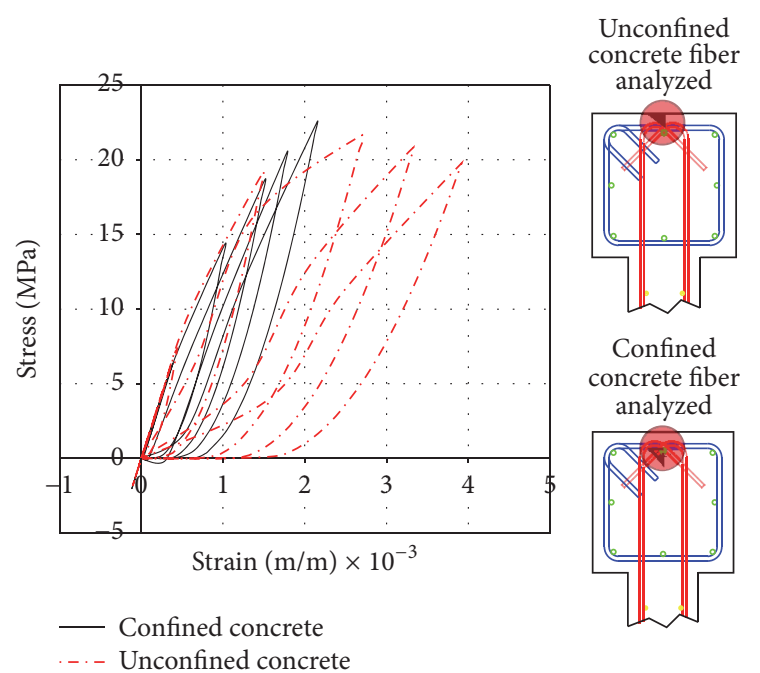

Figure 10: Unconfined and confined concrete, cyclic stress-strain constitutive model.

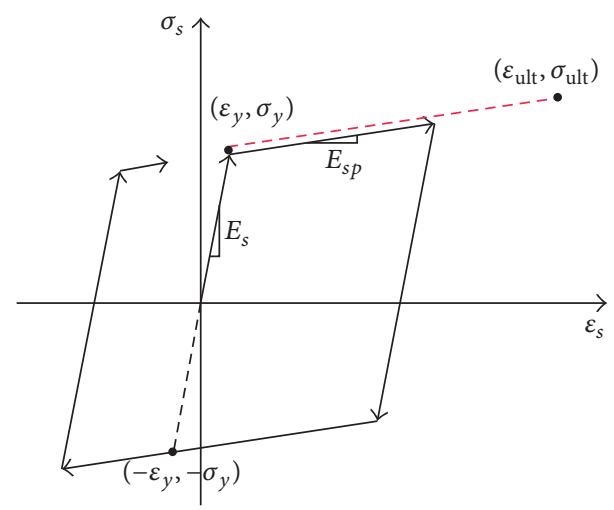

FIGURE 11: Analytical bilinear steel model.
TABLE 8: Menegotto-Pinto steel model parameters.

\begin{tabular}{lcc}
\hline Parameter & Value & Units \\
\hline Modulus of elasticity, $E_{s}$ & 228180 & $\mathrm{MPa}$ \\
Yield strength, $f_{y}$ & 418,547 & $\mathrm{MPa}$ \\
Strain hardening parameter, $\mu$ & 0,00679 & - \\
Transition curve initial shape parameter & 19,7 & - \\
Transition curve shape calibrating coeff. & 18,5 & - \\
Transition curve shape calibrating coeff. & 0,15 & - \\
Isotropic hardening calibrating coeff. & 0 & - \\
Isotropic hardening calibrating coeff. & 1 & - \\
Fracture/buckling strain & 0,1 & - \\
Specific weight & 78 & $\mathrm{KN} / \mathrm{m} 3$ \\
\hline
\end{tabular}

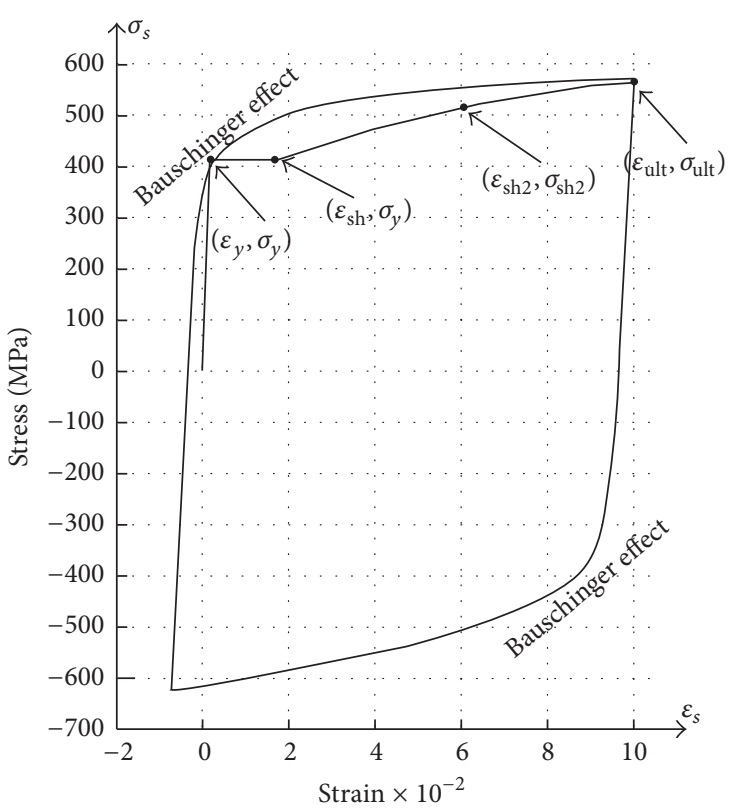

Figure 12: Dodd-Restrepo steel model.

steel models considered in this study is presented. Stl_mp is the most ductile model, and it represents better the pinching effect in every hysteretic loop. Based on the input parameters used, it can be identified in Figure 14 that Stl_dr is the model with the major strength; however it also is the less ductile model.

Analytical Model Calibration. After defining the method and the constitutive models for materials and phenomena used in this study, it is necessary to identify which combination fits better with global experimental results of displacement at the top and force applied. There are two parameters considered to compare the analytical models proposed. They are area enclosed and secant stiffness, and these parameters were defined in every hysteretic loop. The area enclosed permits quantifying the amount of energy dissipated in $\mathrm{KN} \cdot \mathrm{mm}$, and the secant stiffness gives a ratio of force and displacement between limit points in every loop. In Figure 15(a) a comparison is presented between experimental results and 
TABLE 9: Area enclosed error.

\begin{tabular}{lcccc}
\hline Cycle & $\begin{array}{c}\text { Model with } \\
\text { stl_blrebar } \\
\text { [error \%] }\end{array}$ & $\begin{array}{c}\text { Model with } \\
\text { stl_drrebar } \\
\text { [error \%] }\end{array}$ & $\begin{array}{c}\text { Model with } \\
\text { stl_mprebar } \\
\text { [error \%] }\end{array}$ & $\begin{array}{c}\text { Model with } \\
\text { minor area error }\end{array}$ \\
\hline 1 & - & - & - & - \\
2 & - & - & - & - \\
3 & - & - & 28,22 & stl_mp \\
4 & - & 99,97 & 68,45 & stl_dr \\
5 & 28,22 & 31,64 & 91,43 & stl_mp \\
6 & 68,67 & 97,95 & 7,77 & stl_mp \\
7 & 93,03 & 27,92 & 8,31 & stl_bl \\
8 & 10,39 & 23,76 & 9,55 & stl_mp \\
9 & 0,51 & 16,61 & 12,30 & stl_mp \\
10 & 20,14 & 18,03 & & \\
11 & 11,18 & & & \\
\hline
\end{tabular}

TABLE 10: Secant stiffness error.

\begin{tabular}{lcccc}
\hline Cycle & $\begin{array}{c}\text { Model with } \\
\text { stl_blrebar } \\
\text { [error \%] }\end{array}$ & $\begin{array}{c}\text { Model with } \\
\text { stl_drrebar } \\
\text { [error \%] }\end{array}$ & $\begin{array}{c}\text { Model with } \\
\text { stl_mprebar } \\
\text { [error \%] }\end{array}$ & $\begin{array}{c}\text { Model with } \\
\text { minor secant } \\
\text { stiffness error }\end{array}$ \\
\hline 1 & - & - & - & - \\
2 & - & - & - & - \\
3 & - & - & 52,38 & - \\
4 & - & 311,44 & 24,43 & stl_bl y stl_mp \\
5 & 52,38 & 25,04 & 56,22 & stl_mp \\
6 & 24,54 & 60,19 & 24,66 & stl_mp \\
7 & 57,44 & 34,55 & 0,31 & stl_bl \\
8 & 17,23 & 2,16 & 1,88 & stl_mp \\
9 & 12,02 & 2,08 & 2,32 & stl_mp \\
10 & 4,66 & 2,54 & stl_mp \\
11 & 14,24 & & -
\end{tabular}

analytical results for the three steel constitutive models used in this study, so it is easily seen the better approximation of the model which considers stl_mp for rebar. The model presented in Figure 15(c) fits better because stl_mp model gives the option to modify the constitutive material for rebar by including the effect of pinching. In Figure 16 the amount of area enclosed in each loop for the compared models is presented, and in Table 9 which model has less difference in the amount of energy dissipated is defined. In conclusion all the proposed models have good fit for area enclosed; however the model which has stl_mp for rebar has more accuracy. In Figure 17 values of secant stiffness in each loop for the compared models are presented, and in Table 10 which model has less difference of this parameter is defined. The difference between experimental and analytical secant stiffness in the first four cycles is high, and there are good results from cycle 5 onwards. The high difference in the first cycles is because the measure instruments used in experimental test are not good enough to work with small displacements, so there is a loss of accuracy. If the results of the first four cycles obtained in the analytical model are compared with the values obtained with bending and shear elastic theory, there are no differences between them.

Calibrated Model Behavior. After the model was calibrated some data could be obtained by studying the analytical model. SeismoStruct has tools to identify local behavior (stress-strain) in each fiber and then relate this with overall behavior (force-displacement) in the structure. Figure 18 plots the response of base shear and lateral displacement on the wall control point and also has some performance points like yield stress of rebar $\left(\sigma_{y}\right)$, unconfined concrete maximum compressive stress $\left(f^{\prime} c\right)$, and $0.8 f^{\prime} c$. These performance points are located on the Base Shear-Displacement curve by identifying their instances of occurrence. Performance points permit defining damage states and then relate those states with overall behavior like lateral displacement or drifts.

In Table 11 the summary of performance points in the overall behavior of the wall is presented, and a proposed damage state is included by the observation done after experimental test.

In Figure 19 the secant stiffness variation in every loop is presented, and Table 12 shows the calculated reduction of 
TABLE 11: Performance points and states of damage.

\begin{tabular}{lcccc}
\hline Order & Performance point & Displacement $[\mathrm{mm}]$ & Drift & Damage \\
\hline 1st & North, $\sigma_{y}$ & 8,10 & 0,0019 & Slight \\
2nd & South, $\sigma_{y}$ & 7,99 & 0,0019 & Slight \\
3rd & North, $0,8 f^{\prime} c$ & 22,81 & 0,0054 & Moderate \\
4th & South, $0,8 f^{\prime} c$ & 16,80 & 0,0040 & Moderate \\
5th & North, $f^{\prime} c$ & 54,81 & 0,0131 & Extensive \\
6th & South, $f^{\prime} c$ & 109,40 & 0,0260 & Extensive \\
\hline
\end{tabular}

TABLE 12: Secant stiffness reduction.

\begin{tabular}{lccc}
\hline Cycle & $\left({\left.E \sec _{1}-E \sec _{i+1}\right) / E \sec _{1}}\right.$ & Damage & Observations \\
\hline 1 & 0 & - & - \\
2 & 0 & - & - \\
3 & 0 & - & First crack happened (experimental test) \\
4 & 0 & Slight & - \\
5 & 0,63 & Slight & - \\
6 & 0,78 & Slight & First $\sigma_{y}$ happened (analytical model) \\
7 & 0,79 & Moderate & First $0,8 f^{\prime} c$ happened (analytical model) \\
8 & 0,90 & Moderate & First $f^{\prime} c$ happened (analytical model) \\
9 & 0,95 & Extensive & - \\
10 & 0,97 & Extensive & - \\
\hline
\end{tabular}



FIGURE 13: Menegotto-Pinto steel model.

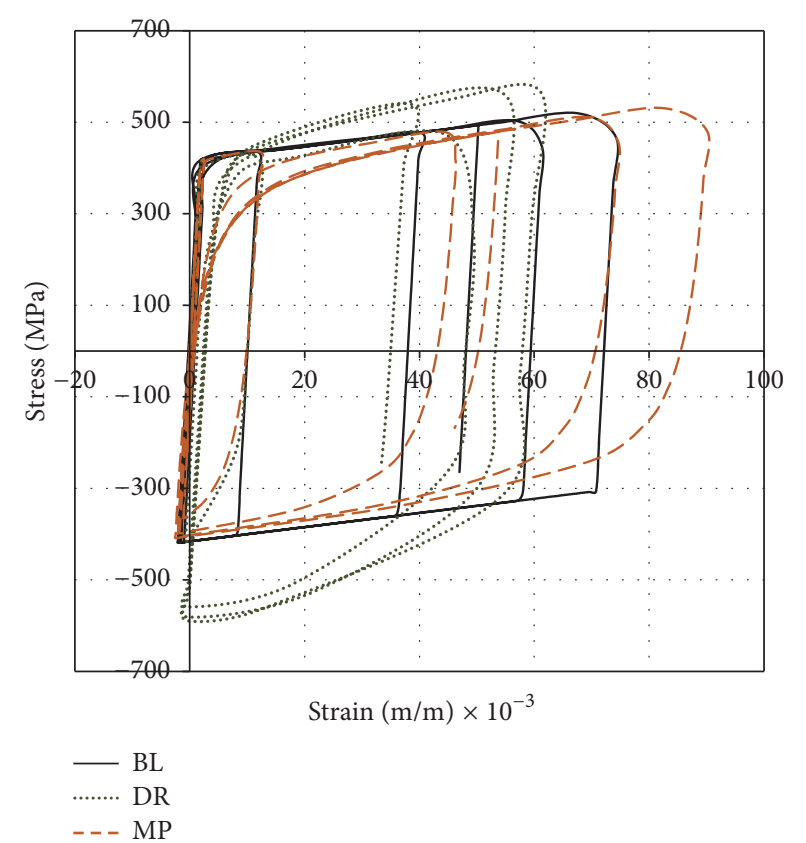

FIGURE 14: Rebar constitutive model comparison in the most strained steel fiber.

From $63 \%$ to $79 \%$ secant stiffness reduction there is slight damage, and from $80 \%$ to $95 \%$ secant stiffness reduction there is moderate damage. Finally from $95 \%$ secant stiffness reduction onwards there is extensive damage.

Linear and nonlinear flexure contribution are produced by the wall body modeled with the fiber method approach secant stiffness. Between cycle 4 and cycle 5 happened the first reduction of $63 \%$ of the secant stiffness, so in this range the first crack happened. The first crack was observed in cycle 4 during the experimental test, and before this cycle there is an elastic behavior in the shear wall. After cycle 5 there is secant stiffness reduction in every loop, and after cycle 11 this reduction was around $98 \%$. 


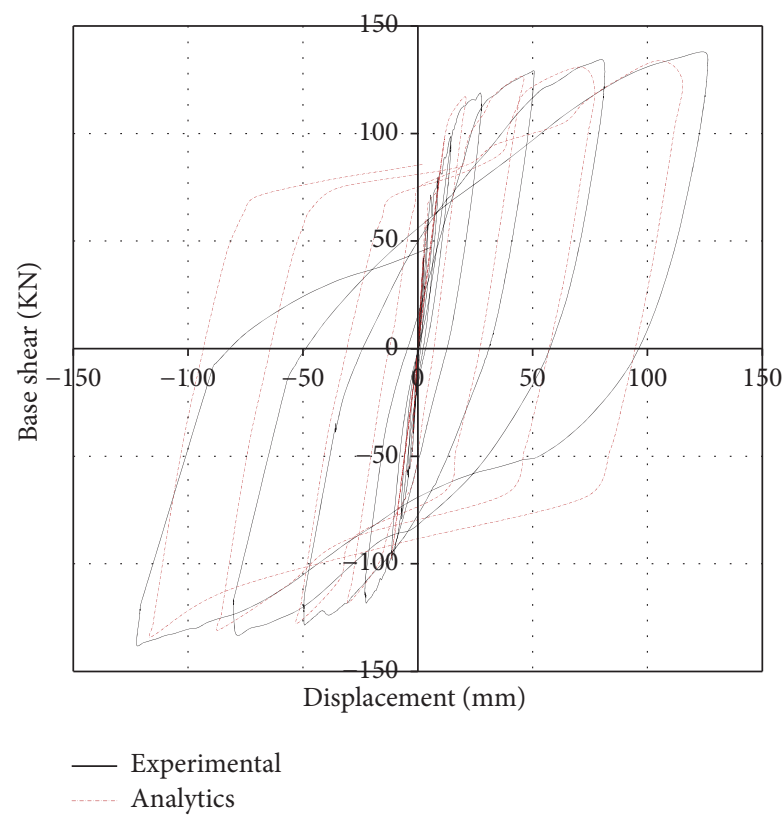

(a) With stl_bl in rebar

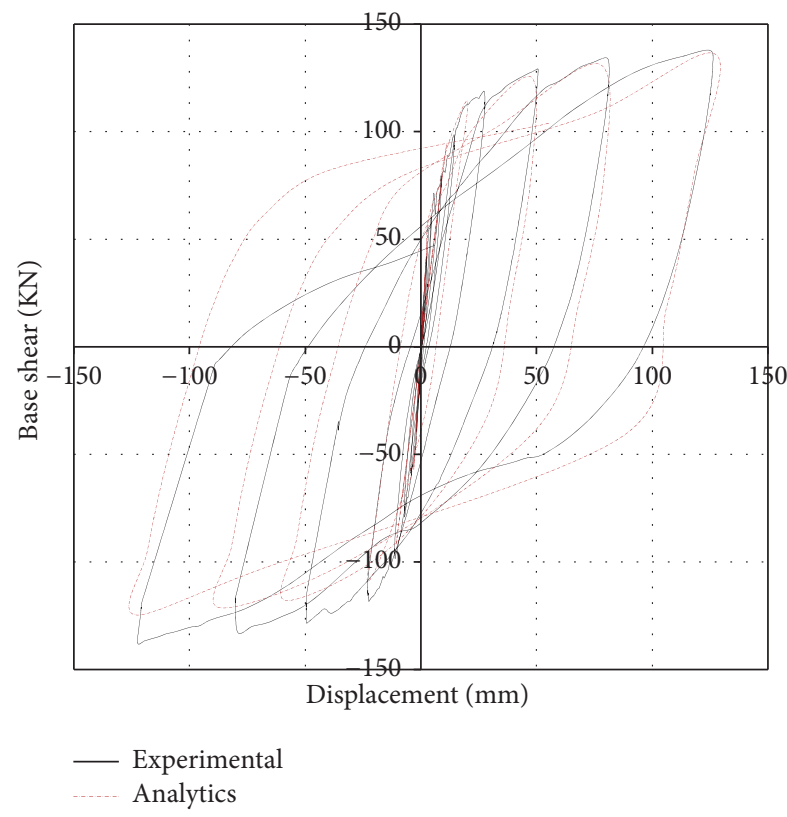

(b) With stl_dr in rebar

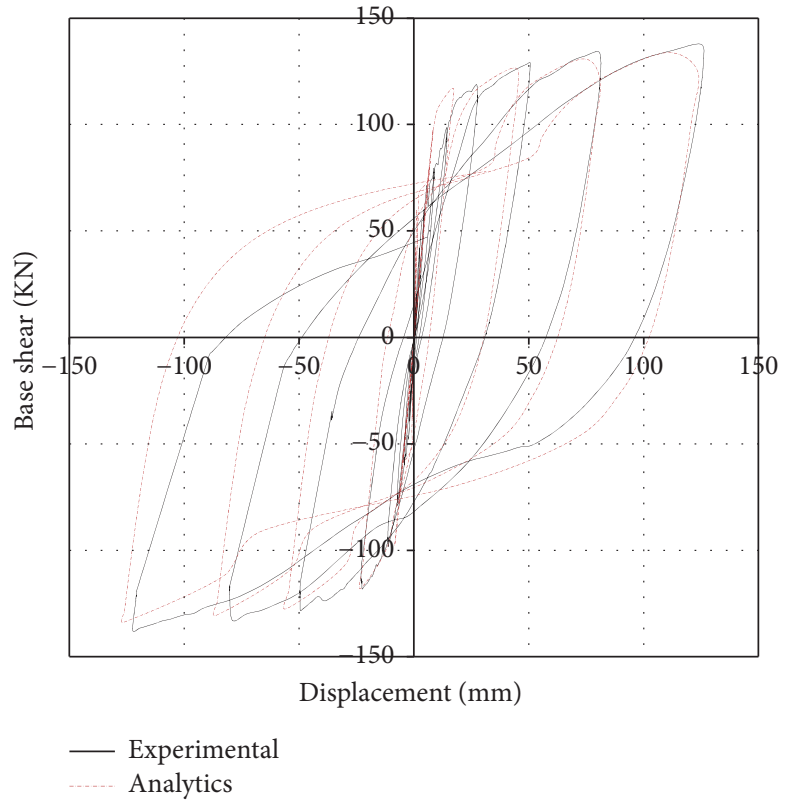

(c) With stl_mp in rebar

FIGURE 15: Base shear-displacement, experimental and analytical data comparison.

while the linear shear contribution is considered by a linear shear spring. In Figure 20, the amount of flexure and shear contribution of total lateral displacement on the wall control point is presented. Before cycle 4 during elastic behavior the flexural contribution is around $88.77 \%$, and shear contribution is around $12.11 \%$. After Cycle 4 with damage happening there is an increase in flexural contribution in cycles 5 to 7 , and then in cycles 8 to 11 the contribution was similar to the first cycles.

\section{Conclusions}

First cracks appear between the lateral applied load of -four tons and + six tons; they are caused by the bending moment near the wall base. Cracks tend to be horizontal, and they are along its boundary elements and the web of the shear wall. At the end of the test, a horizontal crack developed at the bottom of the shear wall confirms a flexural failure. Furthermore, it shows cracks over $60 \%$ of its height, and cracks at the bottom have more than two millimeters of thickness. 


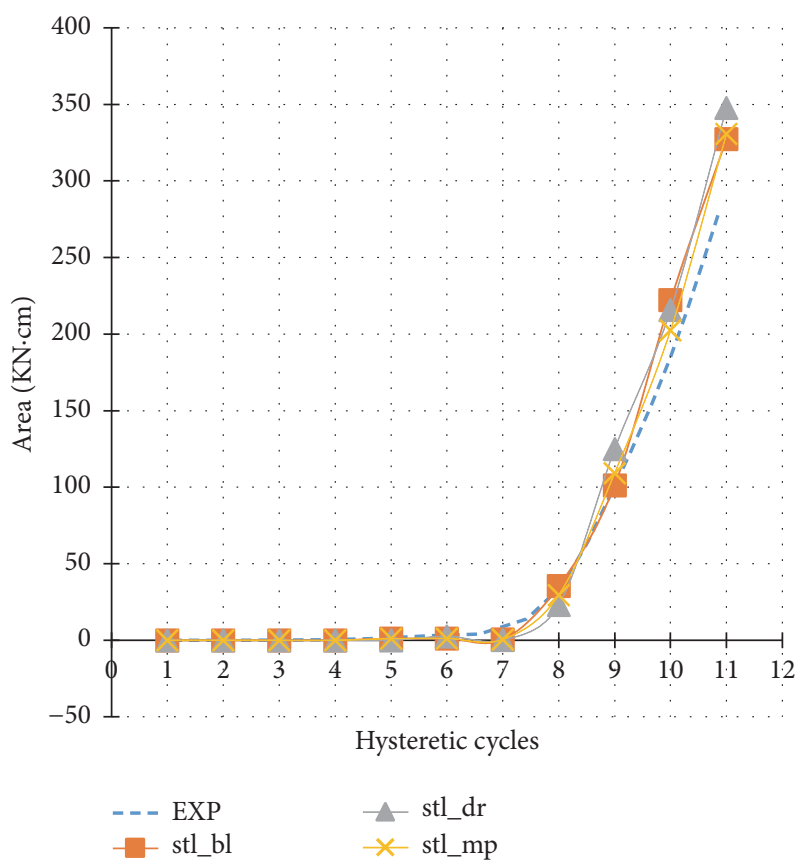

FIGURE 16: Area enclosed in every loop.

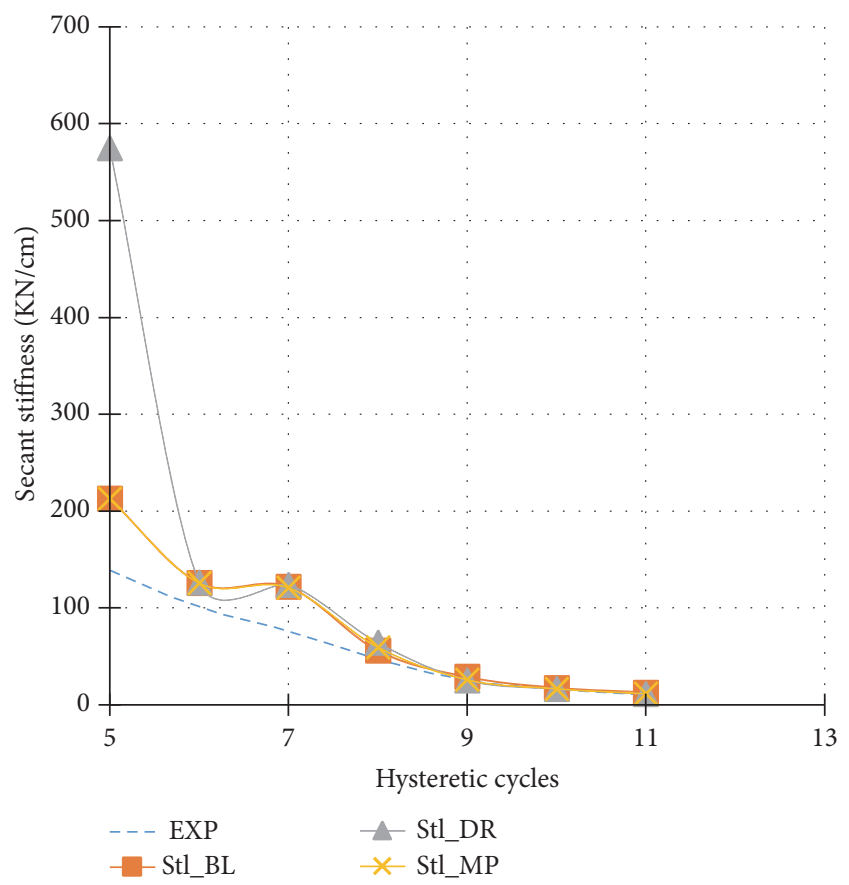

FIGURE 17: Secant stiffness in every loop.

This slender shear wall has high bending contribution on linear and nonlinear lateral displacements, being more than $88 \%$ of the total displacement on each cycle. Most of the response was produced by bending in both experimental and analytical results; however to obtain more accurate results it is necessary to include a linear shear deformation link in the analytical model.

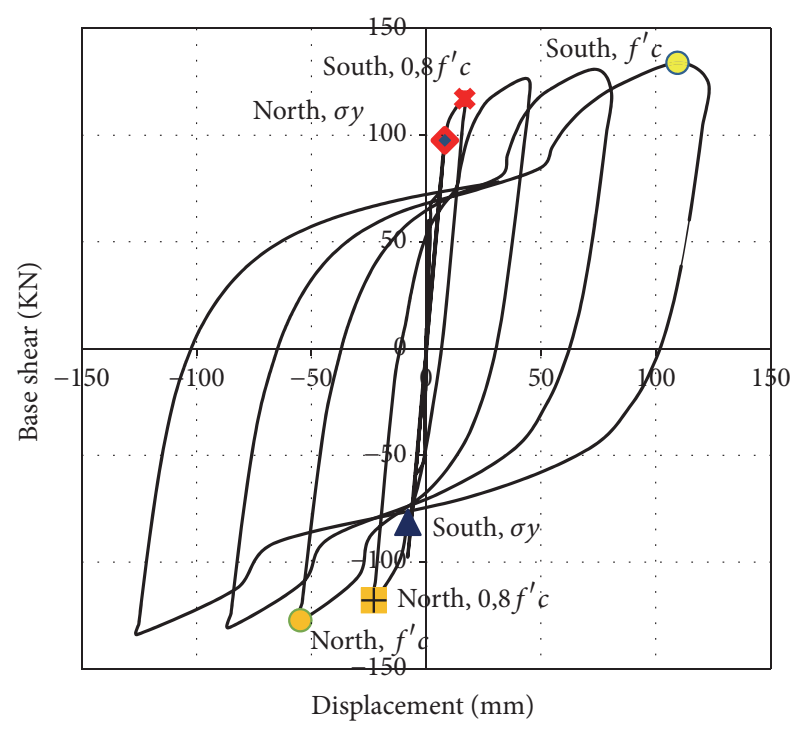

FIGURE 18: Base shear-lateral displacement and performance points.

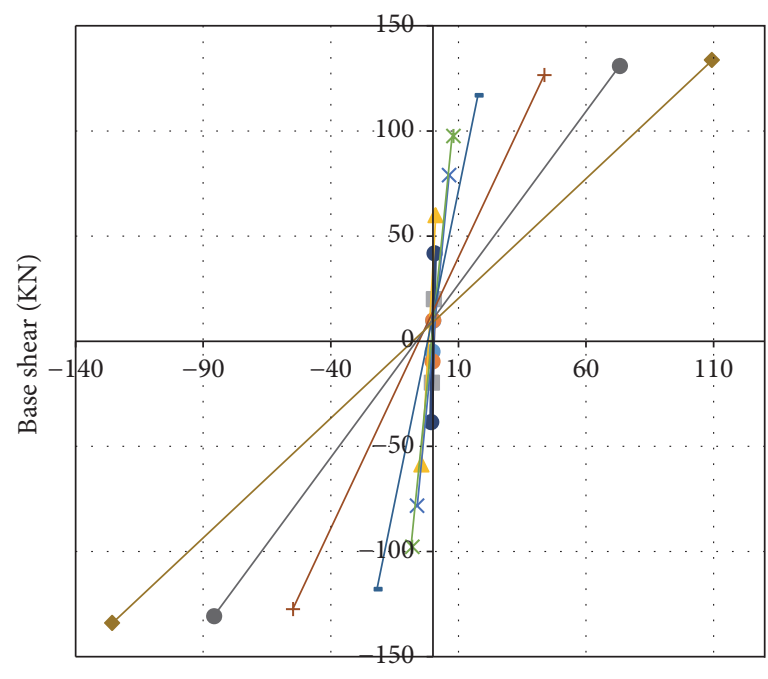

Displacement (mm)

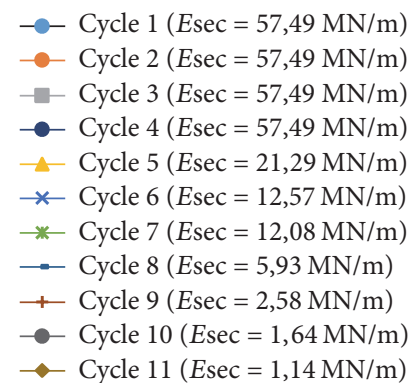

FIGURE 19: Secant stiffness variation.

Hysteretic nonlinear behavior on the structure tested was the result of nonlinear effects considered in concrete and rebar constitutive materials because the shear spring used in the analytical model had linear behavior in each cycle.

The yield of rebar occurs just before observing moderate damage. The reason must be because the rebar loses stiffness 


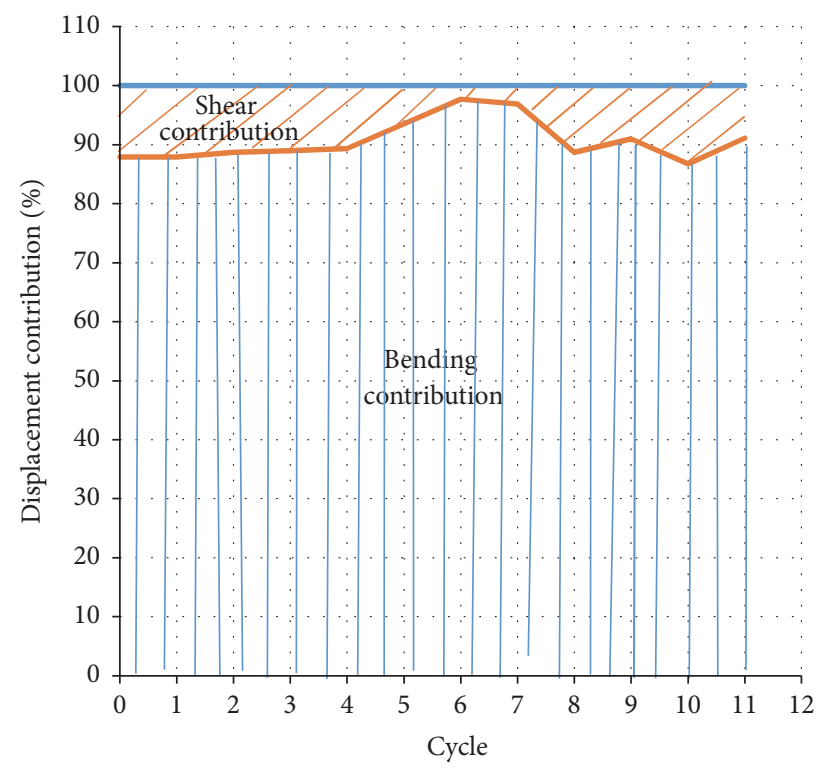

Figure 20: Bending and shear contribution.

then forces are conveyed to concrete, and the loss of stiffness in the steel allows greater deformations in the structure.

Although the hysteretic capacity curve changes its shape with different models of steel, the secant stiffness has no significant variation with the steel models used in this study.

The steel model is one important factor for calibrating the hysteretic energy dissipation in the slender shear wall studied in this document. Steel models do not improve the calibration of static structural properties like stiffness, strength, and displacement, but they can get a better approximation of dynamic properties like hysteretic energy dissipation.

This study uses only one concrete material model because [10] is considered as one of the most robust analytical models for representing hysteretic nonlinear concrete behavior, and this document wants to focus on the influence of steel material model as the main parameter of variation.

Performance points obtained by the analysis of uniaxial nonlinear behavior of the materials used in this document can be considered as reference points to identify the propagation of damage in slender shear walls.

\section{Conflicts of Interest}

The authors declare that there are no conflicts of interest regarding the publication of this article.

\section{References}

[1] Y. J. Park, A. M. Reinhorn, and S. K. Kunnath, IDARC, Inelastic Damage Analysis of Reinforced Concrete Frame-ShearWall Structures, National Center for Earthquake Engineering Research, 1987.

[2] J. W. Wallace and J. P. Moehle, "Ductility and detailing requirements of bearing wall buildings," Journal of Structural Engineering, vol. 118, no. 6, pp. 1625-1644, 1992.
[3] N. Ile and J. M. Reynouard, "Nonlinear analysis of reinforced concrete shear wall under earthquake loading," Journal of Earthquake Engineering, vol. 4, no. 2, pp. 183-213, 2000.

[4] P. A. Hidalgo, C. A. Ledezma, and R. M. Jordan, "Seismic behavior of squat reinforced concrete shear walls," Earthquake Spectra, vol. 18, no. 2, pp. 287-308, 2002.

[5] J. H. Thomsen IV and J. W. Wallace, "Displacement-based design of slender reinforced concrete structural walls - Experimental verification," Journal of Structural Engineering, vol. 130, no. 4, pp. 618-630, 2004.

[6] R. K. L. Su and S. M. Wong, "Seismic behaviour of slender reinforced concrete shear walls under high axial load ratio," Engineering Structures, vol. 29, no. 8, pp. 1957-1965, 2007.

[7] J. S. Kuang and Y. B. Ho, "Seismic behavior and ductility of squat reinforced concrete shear walls with nonseismic detailing," ACI Structural Journal, vol. 105, no. 2, pp. 225-231, 2008.

[8] M. Menegotto and P. E. Pinto, "Method of analysis for cyclically loaded R.C. plane frames including changes in geometry and non-elastic behaviour of elements under combined normal force and bending," in Proceedings of the Symposium on the Resistance and Ultimate Deformability of Structures Acted on by Well Defined Repeated Loads, International Association for Bridge and Structural Engineering, pp. 15-22, Zurich, Switzerland, 1973.

[9] L. L. Dodd and J. I. Restrepo-Posada, "Model for predicting cyclic behavior of reinforcing steel," Journal of Structural Engineering (United States), vol. 121, no. 3, pp. 433-445, 1995.

[10] J. B. Mander, M. J. N. Priestley, and R. Park, "Theoretical stress-strain model for confined concrete," Journal of Structural Engineering, vol. 114, no. 8, pp. 1804-1826, 1988.

[11] SeismoSoft. (January 26, 2017). SeismoStruct-A Computer Program for Static and Dynamic nonlinear analysis of framed structures. http://www.seismosoft.com.

[12] ACI 318S-14, Requisitos de reglamento para el Concreto Estructural y Comentario, American Concrete Institute.

[13] FEMA 306, Evaluation of Earthquake Damaged Concrete and Masonry Wall Buildings.

[14] B. S. Smith and A. Girgis, "Simple analogous frames for shear wall analysis," Journal of Structural Engineering (United States), vol. 110, no. 11, pp. 2655-2666, 1984.

[15] F. F. Taucer, E. Spacone, and F. C. Filippou, A fiber Bem-Column Element for Seismic Response Analysis of Reinforced Concrete Structures, Earthquake Engineering Research Center, Berkeley, Calif, USA, 1991.

[16] A. Neuenhofer and F. C. Filippou, "Plastic hinge integration method for force-element models," Journal of Structural Engineering, vol. 7, no. 123, pp. 958-966, 1997.

[17] K. J. Elwood, "Modelling failures in existing reinforced concrete columns," Canadian Journal of Civil Engineering, vol. 31, no. 5, pp. 846-859, 2004.

[18] J. E. Martinez-Rueda and A. S. Elnashai, "Confined concrete model under cyclic load," Materials and Structures/Materiaux et Constructions, vol. 30, no. 197, pp. 139-147, 1997.

[19] M. Bruneau, C. M. Uang, and S. R. Sabelli, Ductile design of steel structures, McGraw Hill Professional, 2011.

[20] F. C. Filippou, E. P. Popov, and V. V. Bertero, "Effects of bond deterioration on hysteretic behaviour of reinforced concrete joints," Tech. Rep. EERC 83-19, Earthquake Engineering Research Center, University of California, Berkeley, Calif, USA, 1983. 


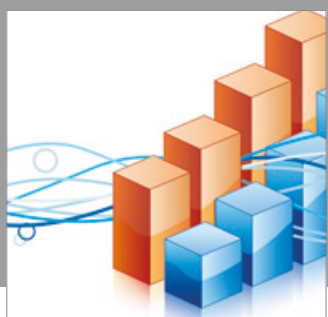

Advances in

Operations Research

vatersals

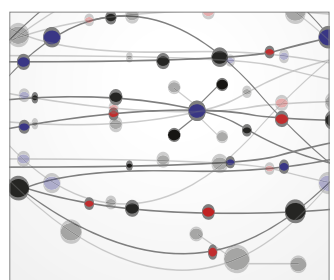

\section{The Scientific} World Journal
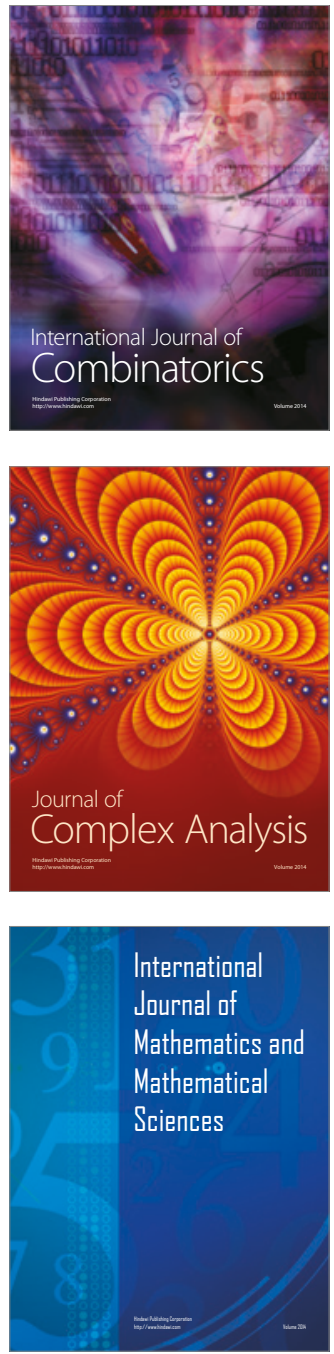
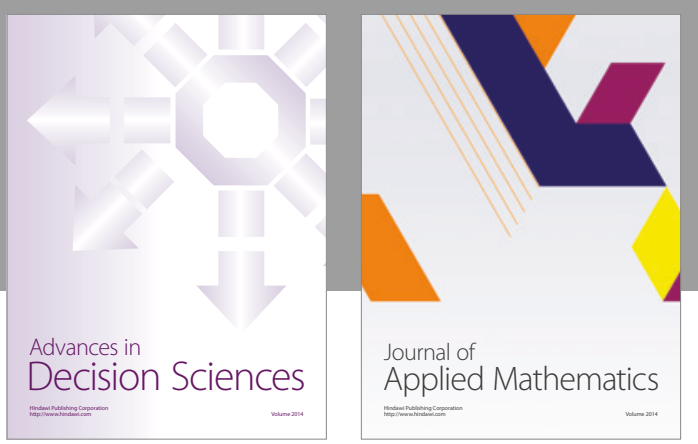

Algebra

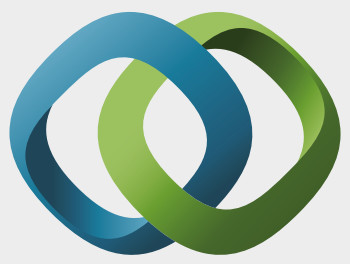

\section{Hindawi}

Submit your manuscripts at

https://www.hindawi.com
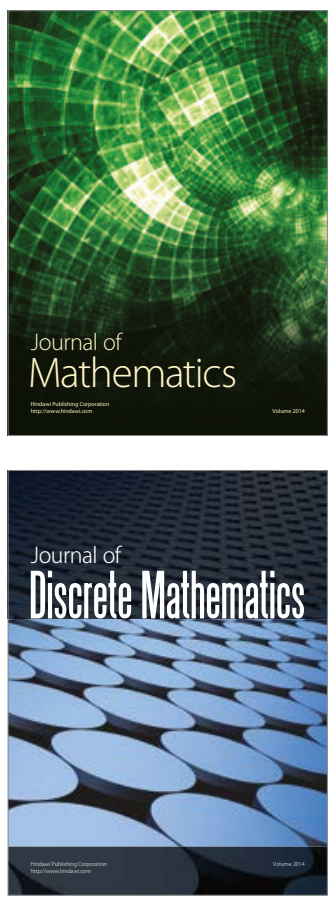

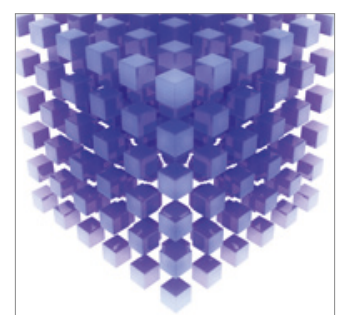

Mathematical Problems in Engineering
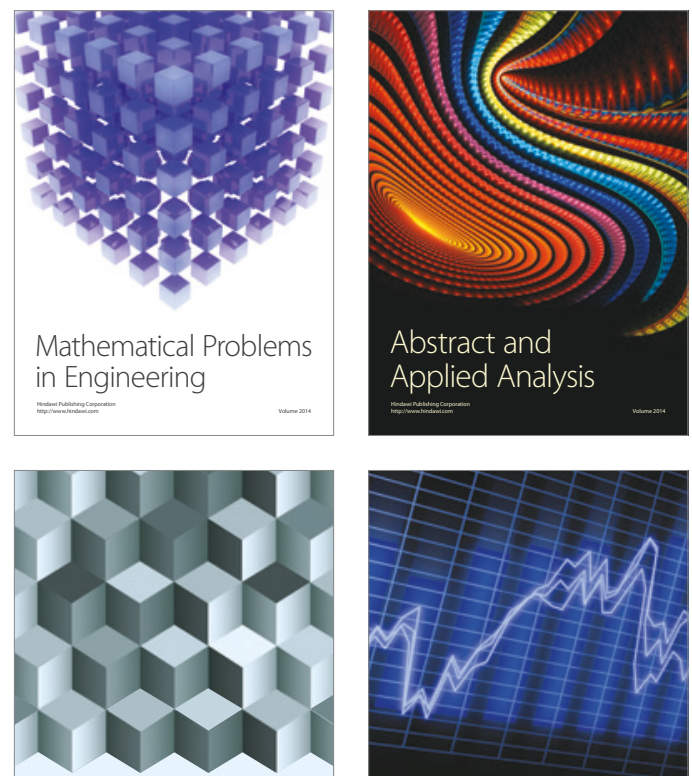

Journal of

Function Spaces

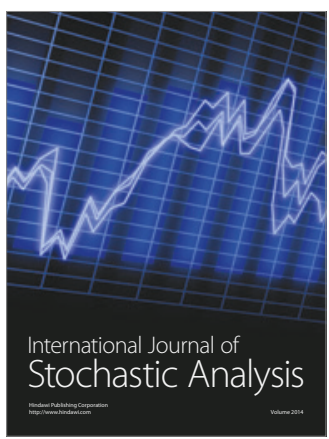

Probability and Statistics
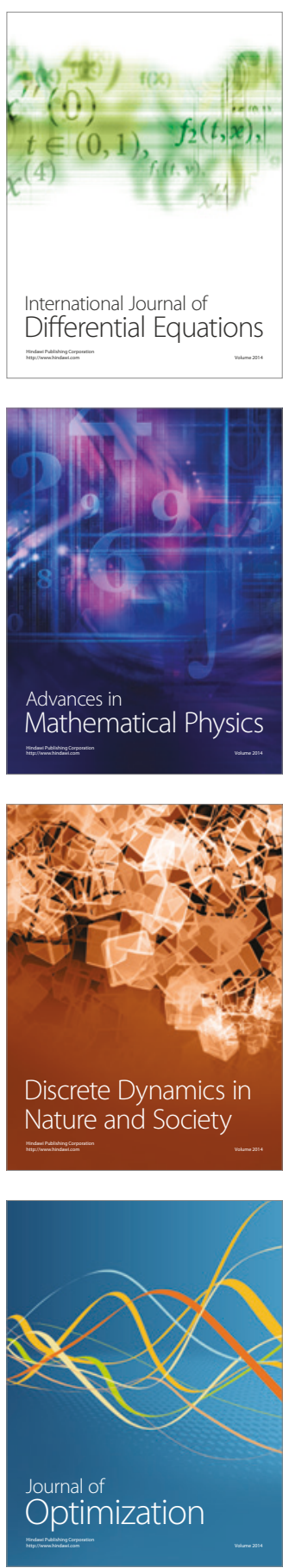